\title{
Identifying Regional Behavior Impacts of Electricity Generation in Electricity Market with SSNIP and Granger Test
}

\author{
Z. Tavassoli Hojati ${ }^{1}$ and S. F. Ghaderi ${ }^{2}$ \\ ${ }^{1}$ Socio-Economic Systems Engineering, University of Tehran, Tehran, Iran \\ ${ }^{2}$ Department of Industrial Engineering, College of Engineering, University of Tehran, \\ Tehran, Iran
}

\section{Introduction}

A brief glace at the electricity market and considering the methods of supervising its exploitations in different countries illustrate that this market had been managed monopolistically by governments for several years. Regarding restructuring and evolution in the electricity markets happened in many countries in recent years, it is necessary to achieve methodologies in which some trends like market power could be analyzed (Heydari K. 2003). Then decision makers can easily make some decision to prevented unfair behaviors in electricity market and direct it to a pure competitive condition.

A competitive market is characterized as:

1. When a quantity of production of a producer reduced, simply, another producer could replace that. It means that there is an appropriate reservation in the network.

2. New producers could enter to the market easily.

3. The numbers of competitors are enough. It means that they sell their production according to the market price and it also mean that it is them that put the price and no company could change the price by changing the quantity of its production.

4. Market and production information are available as free for sellers and buyers.

Although the attempt to achieve a completely competitive market has not been succeed but it improved the condition of this market considerably. In this way presenting the proper definition of the market, recognizing present markets and relationship between these markets is necessary. Without it, any assessment regarding the market power and changing prices could result confusion in market activities. Furthermore because of particular characteristic of electricity to be non-storable product in large scale, electricity market has to be controlled and monitored by the governments to detect and prevent exercising any market power. In order to achieve this goal, there are some controls and antitrust activities which are done inside and outside of electricity market. A group of techniques are also employed for analysis of prices relation and model design for finding market's boundaries by Granger and SSNIP test.

In this chapter, the conceptions concerning market definition, market power, SSNIP test (as a mechanism for market defining and a good tool for those who provide prices in order to identify related markets they are engage it) and granger test (as a statistical technique using for defining dependent and independent markets and relations between these markets) are 
presented and then the market definition and identification for the related markets in a sample Electricity market are discussed. Presented models as the prediction mean in electricity market are evaluated; finally the results of SSNIP test are compared with the real electricity market database.

\section{A review on function of Iran's electricity market}

Iran's electricity market has been established in 1382 as a wholesaler market. According to electricity market rule, "market adjusting board", "market manager" and "center" constitute three main organs of Iran's electricity structure.

Market manager do electricity transaction, in other words daily administrating energy's market. National network leading and searching center or its assistance (national dispatching) is responsible for leading country's electricity network, also it should make sure that using this network would be safe and secure.

Market adjusting board lead and control electricity market to facilitate economic exchanges as well as solving disputes among market's main members. So market adjusting board can be labeled as Iran's electricity market lawmaker organ. Importance of responsibilities and jurisdiction, necessitate independency of this organ from market's members.

However, the following reasons (especially when the numbers of producers are limited) generally cause the prevention of establishment of competitive market in the field of electricity:

1. Impossibility of electricity storage in mass extent

2. Impossibility of flow power control to desirable course

3. Not balanced distribution (based on the principle of production and consumption) in comparing to other competitive markets:

In a complete competitive market, despite some limitations, usually production is done in the nearest distance from consumption market. But in electricity market production takes place in an area that primary facilities such as primary source of energy and work force are available and there be no environmental issues.

4. Absence of balanced transfer and distribution power system establishment:

Limitations in quantity of transfer lines and distribution of power and also impossibility of new line establishment (because of no economic value or environmental issues) are considered as some other factors which restrain competition in electricity market.

5. Other technical difficulties:

Some difficulties such as limitations power voltage resistance etc could be categorized in the section.

Iran's electricity market programs is indeed about output and input of units, provided that by received information from electricity seller companies some limitations are removed. The input information of this program which is within market manager's jurisdiction is as follows:

- Unit's megawatt and suggested rate of produced energy

- Forecasting network bar: electricity market would have bar information for the whole next day. This includes forecasting bar of national network for 24 hours, forecasting regional electricity companies peak bar hour and regional peak bar hour. In addition, the rate of foreign interchange is known for hour by hour of the next day. The total model of Iran's electricity market is shown at figure 1. 
- Network's limitations: it includes limitations of interchanging among regions, maximum and minimum power stations daily energy, units which should be out and on and identification information of power station units.

The general policy of electricity market program is as follows:

The program starts to solve a non-linear optimization case regarding the information which it has received from seller companies.

After solving optimization case, the program produces a series output. The most important part of them is market production arrangement and average accepted price at each hour. The sellers would announce their proposal to market for each power station unit and for each day by the hour in maximum 10 steps. The information related to forecasting buyers needed service (regional electricity companies) would be announced to market daily and by hour too.

For handling electricity market, there should be received technical information from network leading assistance, including power stations produced energy, information of interchanging lines, production and code of unit status and peak hour, capability by unit and power station, forecasting regional electricity companies bar, frequency fall and rate of black-out and the amount of power stations lack of co-operation with control center.

Figure 1 shows Iran's electricity market model comparing to standard market (Setayesh Nazar M. et al. 2007) Parts who have no boarders has not yet set in motion.

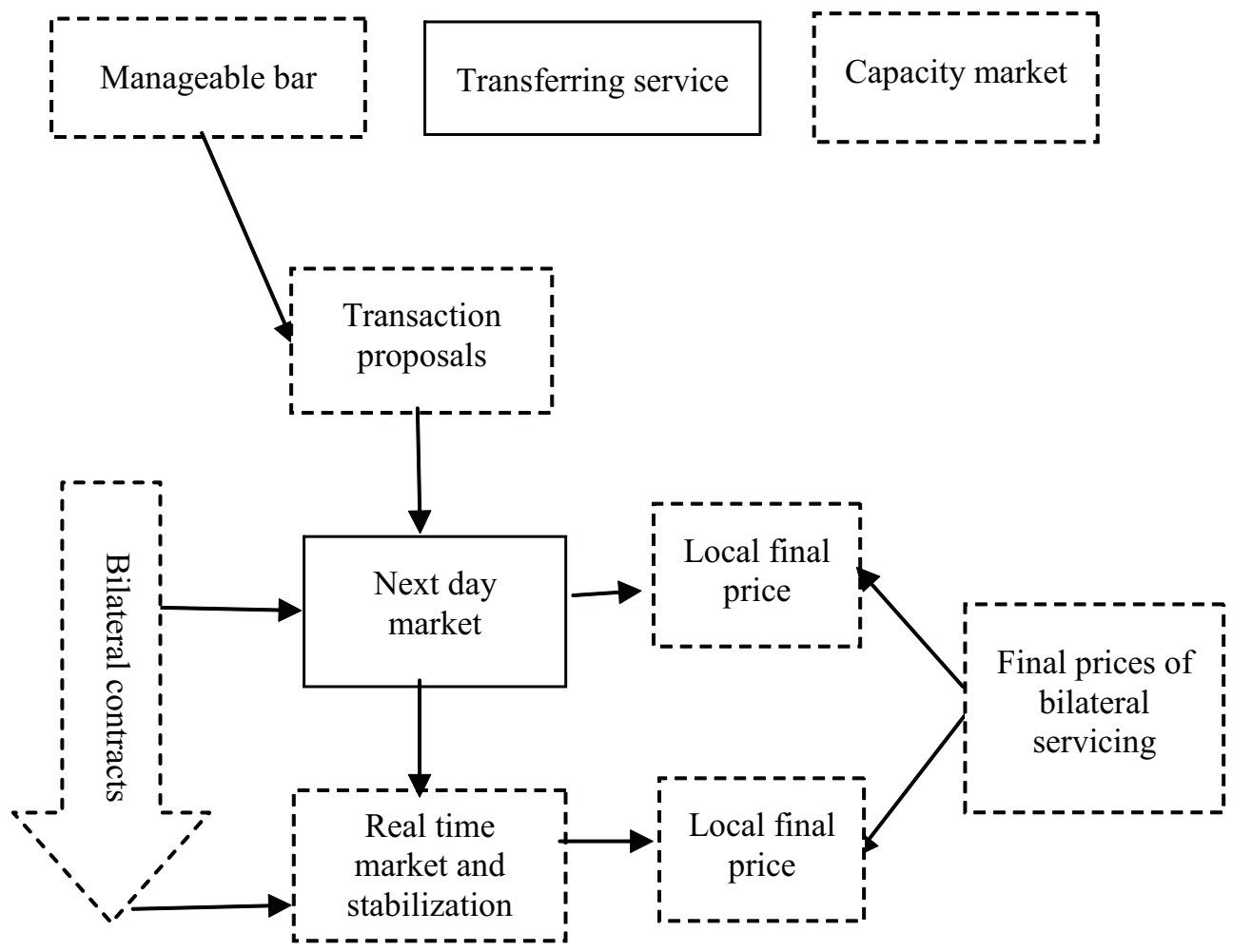

Fig. 1. Iran's electricity market model comparing standard market 


\section{Ways of market's exercising of authority}

After privatization and changing market's structure to new ones, usually there would exist a phenomenon named "market's power". In this phenomenon, seller can change prices to gain more benefit than to competitive prices. In U.S. Department of Justice (DOJ) market power means ability in stabilizing prices at a level upper that competitive level at a known time span. So some factors are used to control market power in U.S. electricity market like short-term administrating of non-elastic demand (supply and demand in short -term span are not elastic, and sometimes this cause privatization and power of market), and preventing privatization expenses, etc. So an operating central market is used for interchanging in network and rate of access to fuel. Here are listed some key factors which prevents market power:

1. Definition of market and parameters which affect on it

2. Test on market potential power and evidences about misusing by market power

3. Enforcing a restriction against those who can exercise authority

To gain this goal, there are some controls and antitrust activities that are done inside and outside of electricity industry, a series of techniques are also employed for analysis of prices relation, economic studies and model design for finding market's boundaries by Granger test and SSNIP.

Main ways of exercising authority by market are:

1. Physical or quantity restriction which needs intentional reduction of suggesting power station unit in market, even if its output be sold higher than final price. This restriction can be done by lack of suggestion, reduction of output level or announcement of unit output.

2. Financial or economic restriction which necessitate proposals with prices higher than competitive prices.

3. Transferring system strategies, which involve existing or intensifying transferring system repletion for increasing market prices in special regions.

Electricity markets have a special structure, so just the above mentioned items do not confirm existence of market power. Market power in electricity industry means ability of restriction for reduction of some units for increasing market prices and more benefit of other units. This definition, however, should be revised when we encounter electricity network boundaries or lack of mitigation. A company can reduce production of some units and cause changes in market prices, so gain more benefits from production of its other units. This is possible by output restriction as well as over production of some units (to exercise transport limitations) to be benefited by higher prices for other units output. There are some other matters which can cause high prices or produce energy for units whose capacity is under normal level and total shortage of reservation.

There are some standards like HHI which are used to recognize existence of market power. Lack of suitable definition on market or dependant markets can lead to wrong recognition of market power. The standards can be employed in market in two ways:

1. ex ante: the time of market's exercising authority

2. ex post: finding out when market power use its ability in disturbing market.

These standards should be limited and reduced to control market power. In U.S. these limitations are placed according to maximum price and limited prices, but none of them had been successful so far (Frayer J et al. 2004). This problem cause producers do not tend to produce electricity. Totally, employing limitation to all producers in market is not suitable; 
it should be done just about those who are able to exercise authority on market and not for producers of dependant markets.

\section{Definition of market}

There are many techniques for defining market which are used for analysis of each market according to its characters. These definitions are offered according to key economic roles of each market.

A separate market enjoys a competitive boarder which separates it from other markets. Finding out market's geographical boarder is possible by estimating whether there is any potential for imaginary market power or not. This is done by SSNIP test which is explained in next parts in details.

In economic discussions the way of refracting imaginary monopoly via substituting from two views is brought up:

- How one product beneficiary would react against changing price of different products?

This discussion is named demand-side substitution. Cross-price elasticity of demand which is shown in figure 2 is used to reply this question.

\section{PX: Price in Spot Markets}

(Product X)

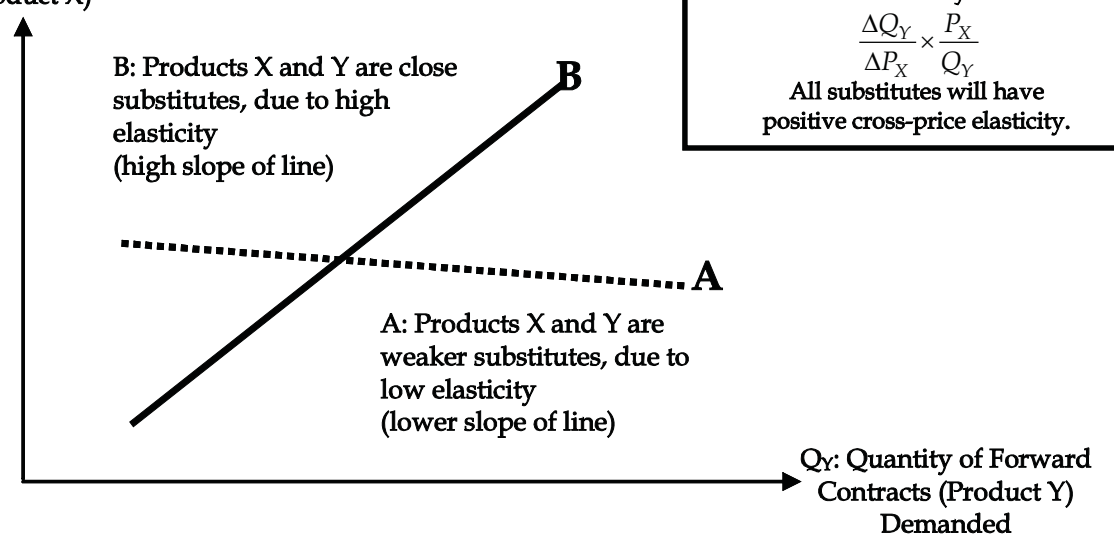

Fig. 2. An example of estimating cross-price elasticity of demand

- How the strategy of other suppliers would change by changing one supplier price? The concept of this question is brought up under the title of supply-side substitution too. This question can be replied by the concept of cross-price elasticity of supply.

Now it is possible to define dependent and independent markets by above mentioned concepts.

- Distinct market is a market including a competitive environment different from other kinds, so it is impossible to eliminate market power by market exercising authority which employs substitution processes. Practical estimation of this market's geographical aspects is done by application of conjectural monopoly policy and SSNIP test.

- Relevant market includes one or more competitive goods. In this market goods can compete and be replaced. Even though the monopolist can increase his price to gain 
benefit but existence of goods which substitute monopoly ones he cannot .This cause products to have little cross-price elasticity of demand. A relevant market compound geography and product aspects and define the result as follows:

- A relevant market compares all products and services which can be substitute by consumer because of characteristics of product, its price or way of consumption.

- A relevant market compare field which companies are worry about offering the products or services.

A traditional definition of market is done based on definition of four aspects of market which is shown in fig. 3 .
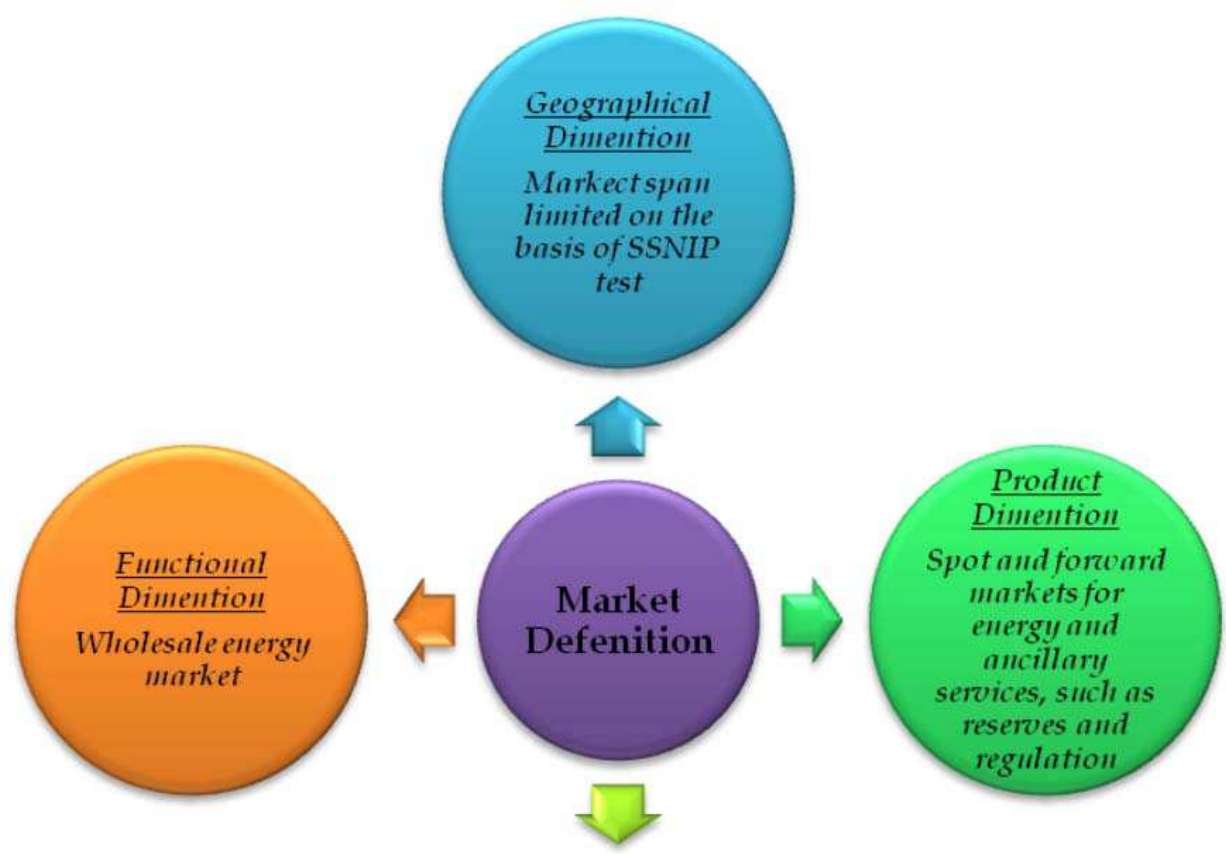

Fig. 3. Four effective aspects in market definition

Local aspect is determined by distinguishing physical boarders of market. In electricity market this aspect is specified by expansion of transport network which is determined by market physical boarders. In market, inter connection among generators do not necessarily 
mean uniform market, but it depends on connective lines between supplier generators in that regions. Geographical aspect can be done by SSNIP test.

Product aspect is determined based on type of that product or service. For example, wholesale in electricity market includes various products and services which has been provided by generators and suppliers of transport service and is necessary for energy wholesale and delivering to consumers. These products can be represented via short-term and long-term contractors or sale -point market daily or without delay. Another discussion here is about peak hours of electricity production and other hours which are not at peak, and whether it is possible to have a separate market for peak hours. For example, lack of correlation in supply diagram in electricity market which is shown in three parts in figure 4 as base load, mid-merit and peak have different offer prices and can show different markets.

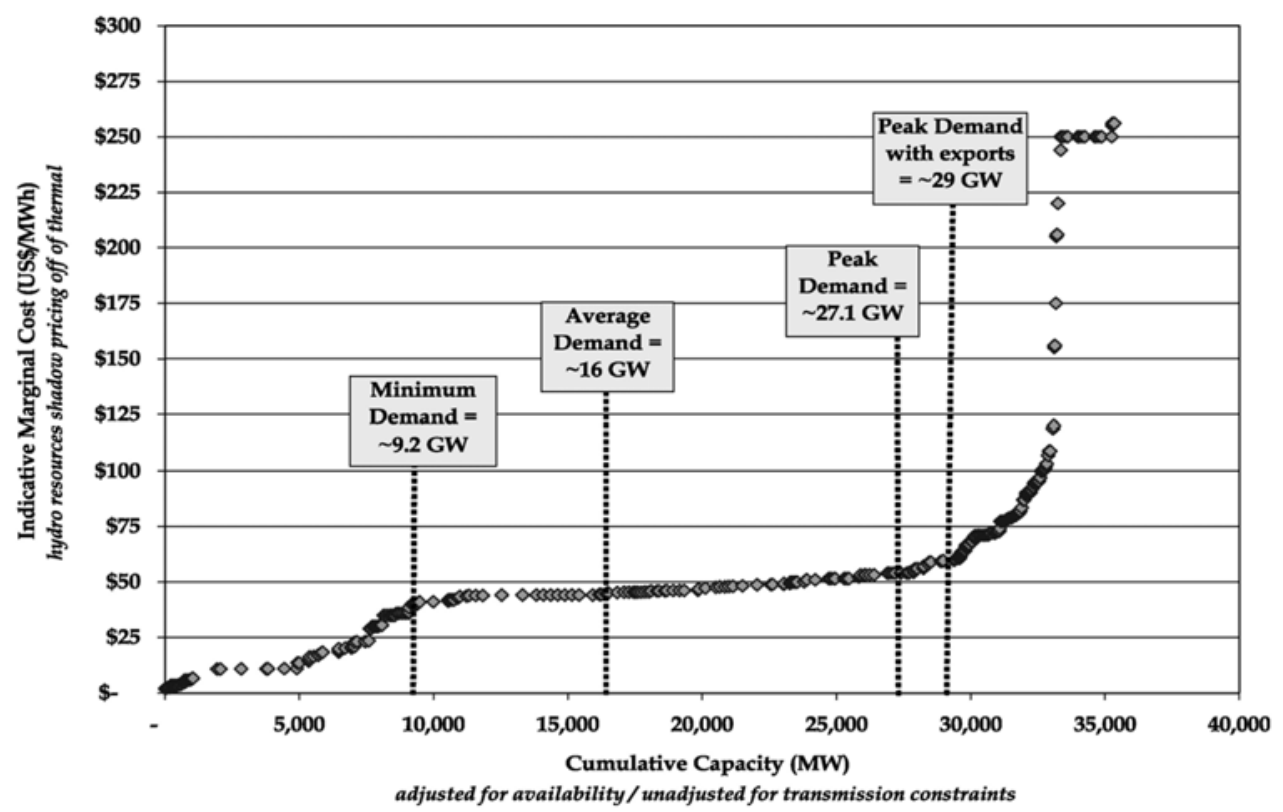

Fig. 4. Supply diagram in US electricity market

Time concept among different products of energy indicates the state of transition in these markets. Although energy is transported by hour and is measured in little profits, but this does not mean market time aspect is one hour or point market (by hour or by five minutes) is a separate market. Point markets are not separate ones because monopoly has not effect on it and consumers can substitute products which they buy form.

In markets throughout the world, a remarkable amount of energy wholesale is done by contacts of bilateral contracts until three years. This can prevent employing a suitable time aspect.

\section{SSNIP test}

In the field of competition rules, before deciding about necessity of companies exercise authority and government interference, SSNIP test is done for determining relevant market 
to a large extent (KATZ M. 2002). This test analyze potential market exercising authority, by analysis of substitute products which are determinative in relevant markets. In addition, competition in market controls market authority. Effective antitrust factors prevent market refraction too, by similar industries alliance, group monopoly and goods monopoly.

Market power is effective when:

1. consumers do not substitute product

2. other suppliers do not increase their supply

This test is used to specify producers who can exercise authority on market or to determine relevant markets boarders, somehow means as "something worth monopolizing". At every market there is a list of products which can be substituted. Each list is monopoly value. This means if there is only one producer for a product, it can increase its price without ability of substituting product by the consumer. This test specifies every relevant market which supposed monopoly or collusion of industry owners which can increase prices effectively. This test results are more useful than Granger's test (Frayer J. et al. 2004) and has been used in electricity market extensively.

\subsection{SSNIP test history}

This test has been directly defined in 1982 by DOJ as a new method for defining markets and a way of measuring market's power.

SSNIP test has been used for the first time in 1992 in UN and in 1997 in European commission to define relevant market.

\subsection{Method of SSNIP test}

This test is done as follows:

1. Offering a definition from supposed market based on product, geography, time and operation aspects

2. Making a model from supposed market including a complete definition of relations in relevant markets which can exist and describe input, supply and demand of possible substitutions at that market

3. Testing the effect of supposed monopoly by little increasing of price ( 5-10 percent)

Using short-term models in this market is a remarkable point of this test in electricity market, so considering time aspect is necessary too. In total, the test limitations (Ogzera 2005) are as follows:

1. considering just competition of prices, ignoring other aspects like quality

2. not being suitable for various kinds of products

3. possibility of mistake based on base point if market be not symmetrical

4. Reduction in production rate do not necessarily means its substitution, it may be because of not consuming by consumers

5. In analysis of competition within product A market, just increasing A price would be considered. For analysis of monopoly state between A and B (both of them in the same market) considering A market is enough.

6. Consideration of market power is considered as competitive pressure of B on A. The controversy of situation is not necessarily true.

\subsection{Measuring results of SSNIP test}

For consideration gained results following items are used: 
1. By practical estimation of critical demand elasticity and comparing it with compounded demand elasticity ( final price would be enough for linear demand function)

2. If demand elasticity cannot be measured, a substitute method would be used named "critical loss" (Katz M. 2006). Critical loss is maximum wasting of a sale which can increase prices effectively. Increasing of prices would be effective when possible loss be lesser than critical loss.

In SSNIP the gained results would be considerable by increasing prices and comparing it with base circumstances, and in the same circumstances with base state, increasing transport price in lines or exercising time aspect in the base environment.

\section{Granger test}

Granger in 1969 proposed a time-series data based approach in order to determine causality. In the Granger-sense $x$ is a cause of $y$ if it is useful in forecasting $y$. In this framework "useful" means that $\mathrm{x}$ is able to increase the accuracy of the prediction of $\mathrm{y}$ with respect to a forecast, considering only past values of $y$.

In doing economic analysis, sometimes, we would like to know whether changes in a variable will have an impact on changes other variables. To use this phenomenon more accurately, we need to learn more about Granger Causality Test. For more information about the mathematical basis of this test, (Gujarati N. 1995) is suggested.

The Granger price test belongs to a genre of statistical techniques used to measure market integration and includes more simplified analysis such as correlation and more sophisticated techniques such as co-integration analysis and error correction models. The base of such tests is derived from Marshallian economic theory, which holds that in open markets (prices encapsulate and characterize all supply and demand dynamics).

Furthermore the Granger causality test takes the analysis of price relationships one step further. Suppose you have a regression model explains the current price of a product by fitting a curve to the historical prices in time series format of that product ex. electricity. Granger's idea explores whether you could significantly increase the descriptive power of this regression analysis for the price of one product by including the price of another product. Formally, Granger causality is said to be not present when the relationship between two variables, $X$ and $Y$, when: $f\left(X_{t} / X_{t_{-} 1}, Y_{t_{-} 1}\right)=f\left(X_{t} / X_{t_{-} 1}\right)$.

There are three possible deductions from the econometric analysis:

- Unidirectional Granger causality from Y to X (or vice versa)

- Feedback or Bilateral Granger causality

- Independence

Granger causality test has also has applied in antitrust cases in the U.S. for the purpose of delineating Electricity market boundaries, on a product, geographical, and functional dimension by (Frayer J et al. 2004). This test also used for identifying of causality of California's electricity and natural-gas (Chi-Keung W. et al 2006), Electricity consumption and economic growth (Yemane W. 2006) and many other cases.

\section{Implementation in Iran electricity market}

By considering and administrating Iran electricity market to model it, a complex solution should be modeled like transport system limitations and its special circumstances on 
market. This matter causes analysis and exact simulations. Limitations which controls market should be considered completely in its model, otherwise, gained results from simulation would not be trustful (Tabei S. M. 2005). Iran's electricity market have 7 regions which each of them enjoys some region regional electricity which is shown in regions (table 1), in regional electricity (table 2) and in network graphical show in Iran electricity market.

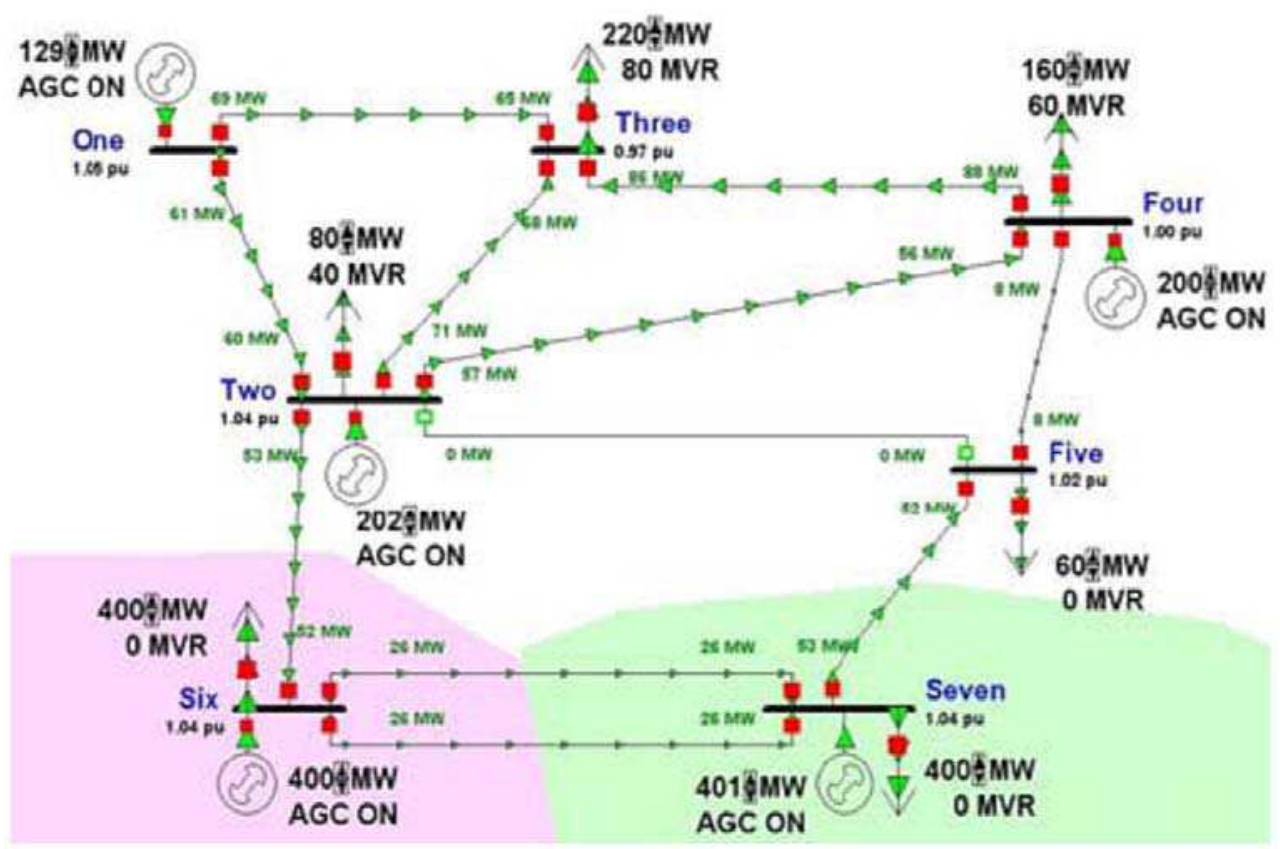

Fig. 5. Graphical show of considerable network

\begin{tabular}{|c|c|}
\hline Region's number & Region's name \\
\hline 1 & Azarbaijan \\
\hline 2 & Markazi \\
\hline 3 & Shomal \\
\hline 4 & Khorasan \\
\hline 5 & Sistan \\
\hline 6 & Gharb va bakhtar \\
\hline 7 & Jonobe shargh \\
\hline
\end{tabular}

Table 1. Regions of Iran's electricity market

Electricity cannot be saved by vast scale and electricity production and distribution management should schedule for utilization and optimal investment according to comparison of supply with energy demand. Therefore for future projects, foresight of bar 
have a special importance and its fault rate should be decreased as possible. Therefore, by initiating electricity market in Iran network, regional electricity companies should anticipate and give whole included network hour by hour consumption needs. This anticipation has been done in Iran electricity market by three states:

1. Anticipation normal days according to finding out similar days

2. Anticipation special days according to finding out similar days

3. Anticipation days after special day according to finding out similar days

\begin{tabular}{|c|c|c|}
\hline Region's number & Region's name & $\begin{array}{c}\text { Number of } \\
\text { related region }\end{array}$ \\
\hline 1 & Azarbaijan & 1 \\
\hline 2 & Esfehan & 2 \\
\hline 3 & Bakhtar & 6 \\
\hline 4 & Tehran & 3 \\
\hline 5 & Khorasan & 4 \\
\hline 6 & Khozestan & 2 \\
\hline 7 & Zanjan & 3 \\
\hline 8 & Semnan & 3 \\
\hline 9 & Sistan and balochestan & 5 \\
\hline 10 & Gharb & 6 \\
\hline 11 & Fars & 2 \\
\hline 12 & Kerman & 7 \\
\hline 13 & Gilan & 3 \\
\hline 14 & Mazandaran & 3 \\
\hline 15 & Hormozgan & 7 \\
\hline 16 & Yazd & 7 \\
\hline 17 & Kish free region & \\
\hline & & \\
\hline & Mron & \\
\hline
\end{tabular}

Table 2. Regional electricity of Iran's electricity market

According to analysis done on Iran network bar inputs, bar behavior diagram is different during the weak and is similar in back-to- back weeks. Results of anticipation for Iran cross country network bar inputs and comparison with nerves network anticipation alongside with master phase system has been shown in figure number 6 till 11 (Vahabi A. et al. 2007). According to electricity market rule, hours are distributed according to warm and cold months as well as consumption capacity as following table.

\begin{tabular}{|l|c|c|c|}
\hline & Low bar hours & Normal hours & Peak hours \\
\hline Warm months & $1-8$ & $9-20$ & $21-24$ \\
\hline Cold months & $\begin{array}{c}1-5 \\
21-24\end{array}$ & $6-17$ & $18-21$ \\
\hline
\end{tabular}

Table 3. Hours distribution based on consumed bar according to electricity market rule 


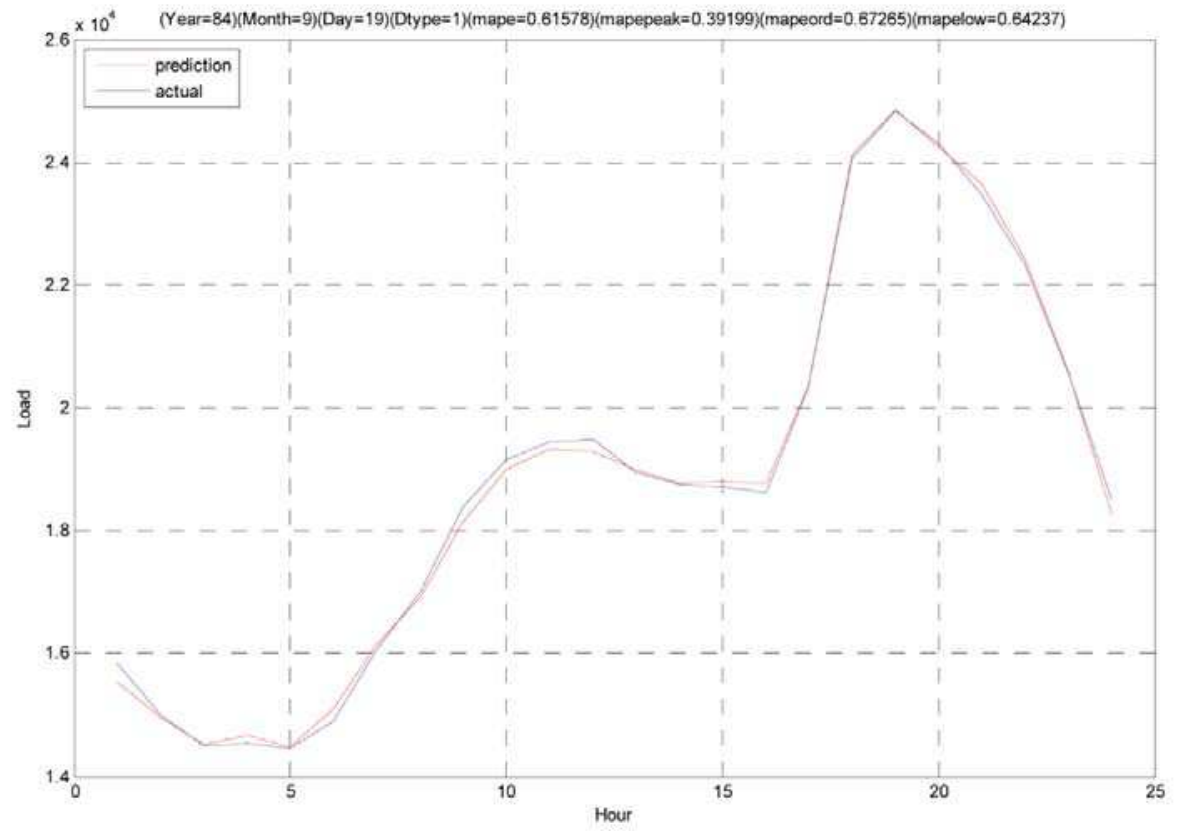

Fig. 6. Anticiption diagram and real bar curve for Saturday

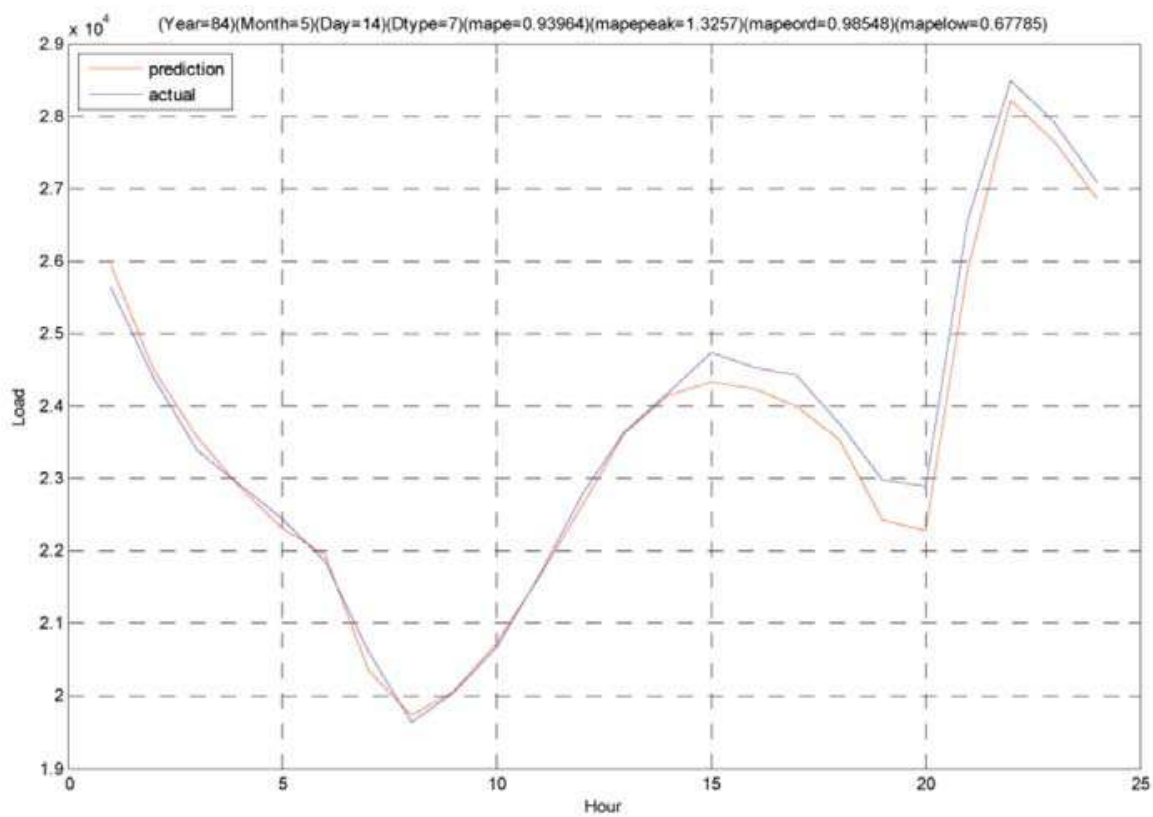

Fig. 7. Anticiption diagram and real bar curve for Friday 


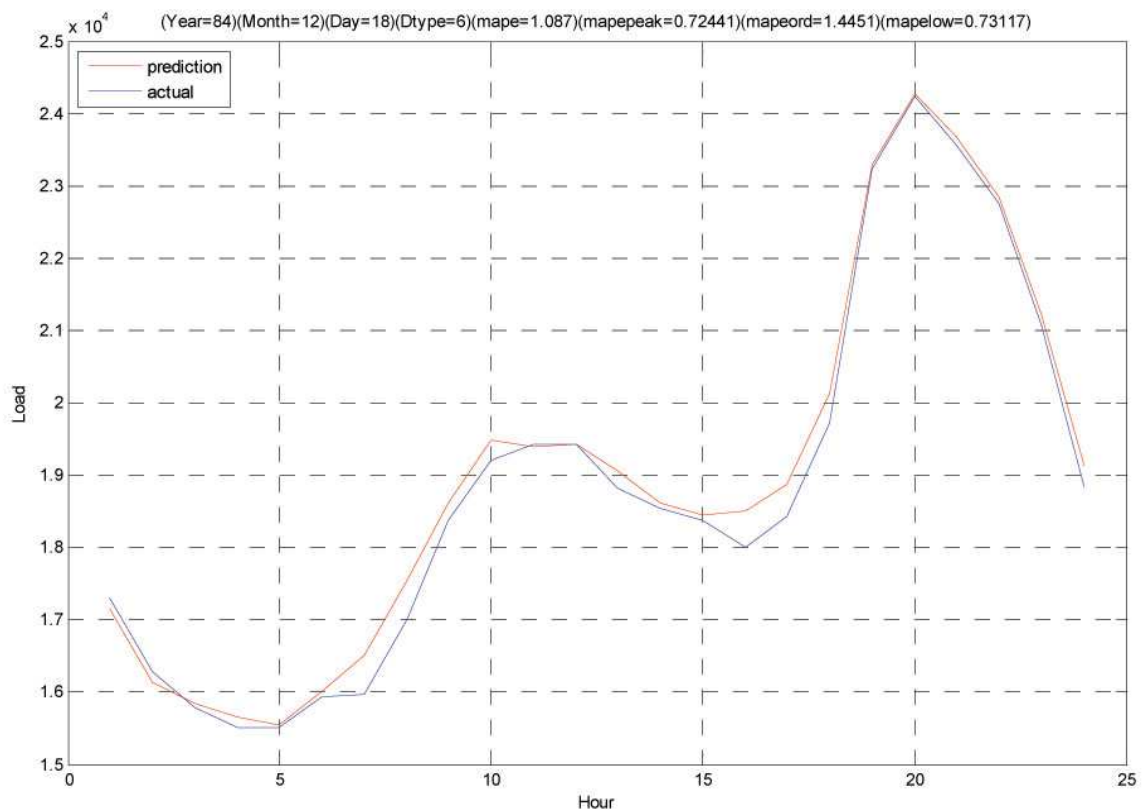

Fig. 8. Anticiption diagram and real bar curve for Thursday

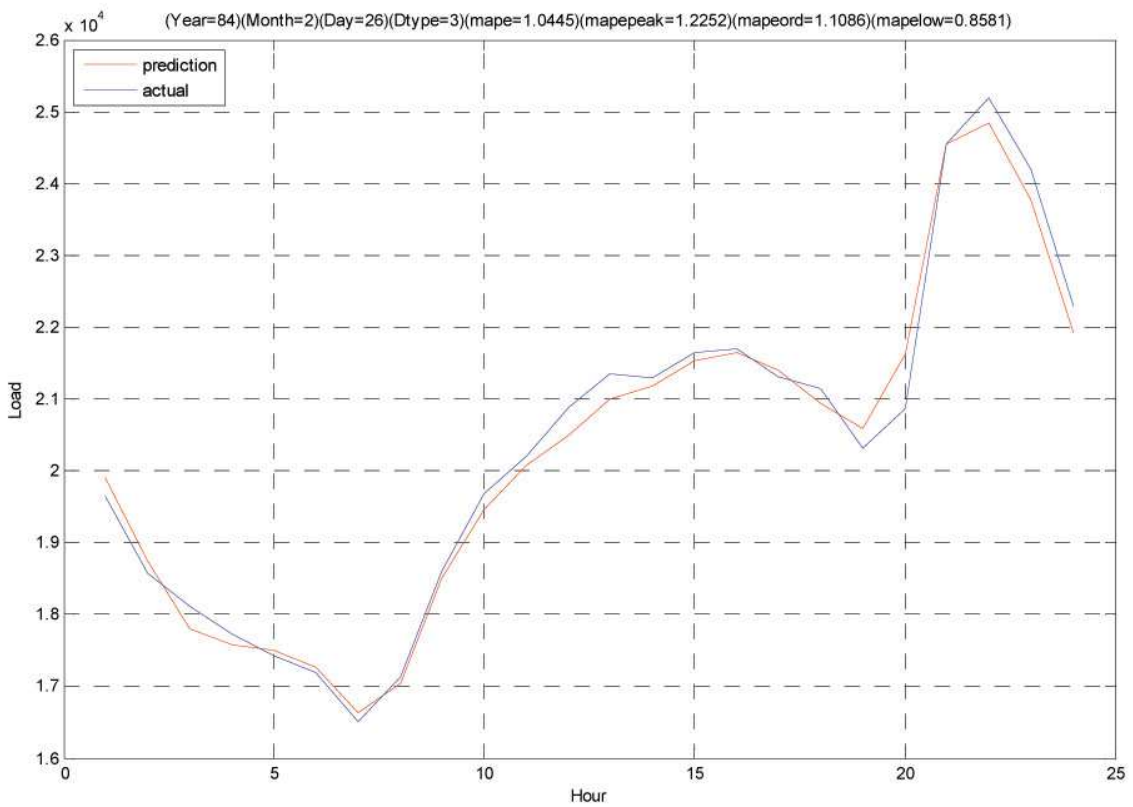

Fig. 9. Anticiption diagram and real bar curve for Monday 


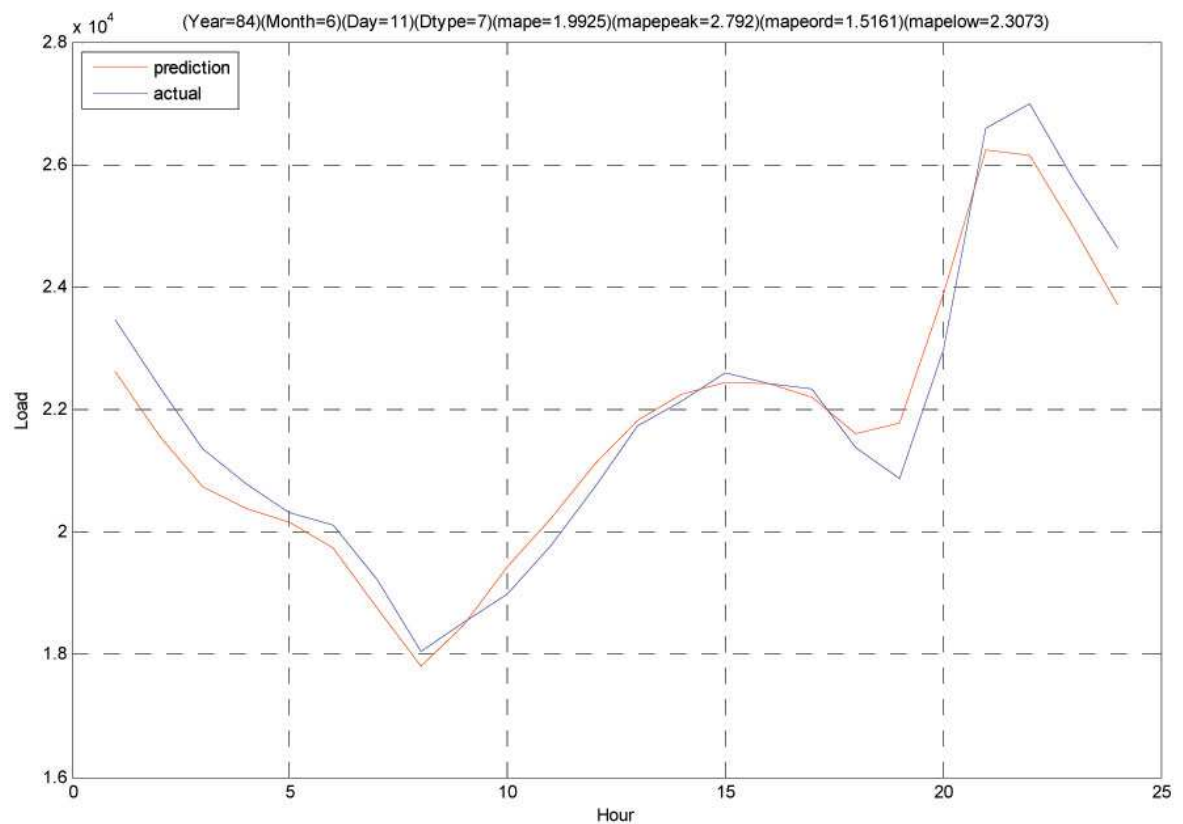

Fig. 10. Anticiption diagram and real bar curve for special lunar day

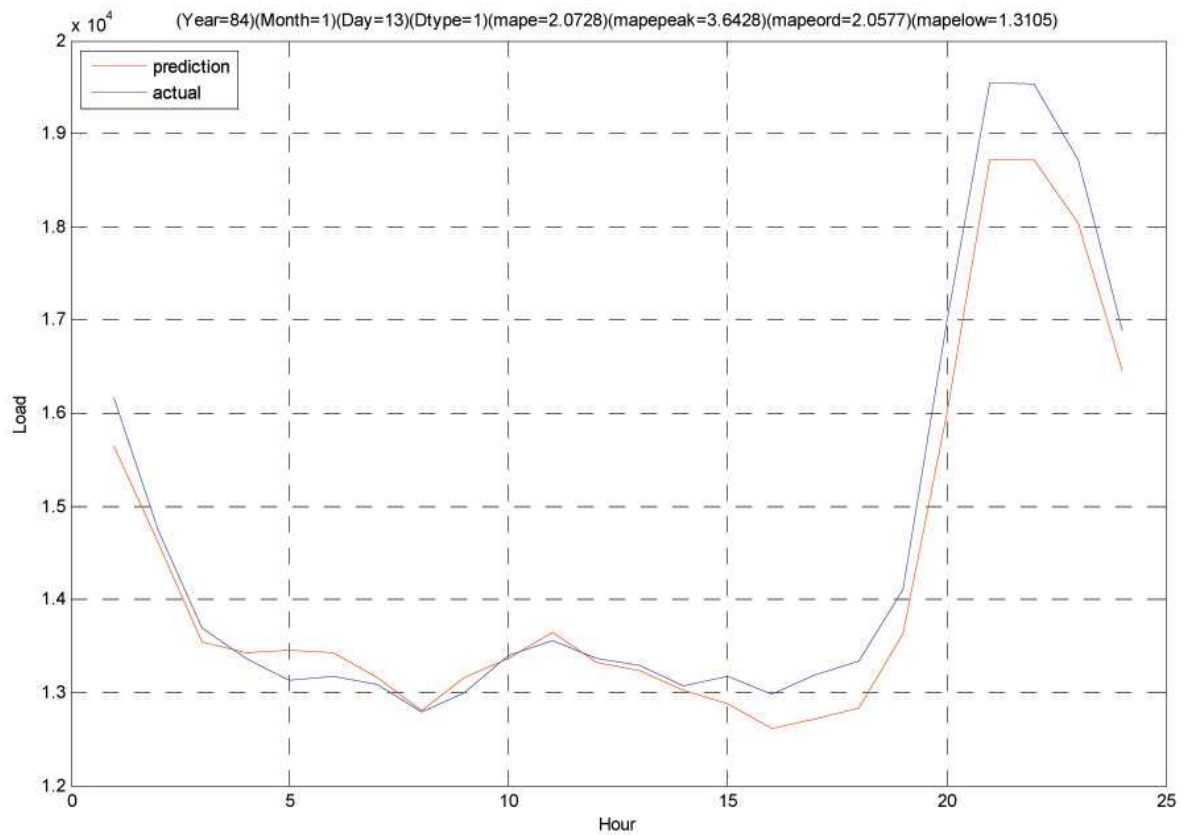

Fig. 11. Anticiption diagram and real bar curve for special solar day 
Network has been distinguished with three different colors as is shown in figure 5. In this figure each bas indicate a region in market. A simple network has been simulated by a Microsoft (Setayesh Nazar M. et al. 2007), and it has been tried to analyze production and lines capacity, their effects on network, and electricity power potential in various states. The results show Iran electricity network includes two parts in north and south. After considering possibility of market exercising authority and its indicators in each region, some ways about reduction of market power in Iran electricity market has been brought up as follows:

1. management of interrupted bars

2. increasing number of power stations

3. increasing of transport lines

4. accumulation management

In another simulation model (Izadi F. \& Puyan S.A. 2002) done in Iran electricity market, at first final expense of each operator is calculated as follows.

$$
S(p)=\frac{1}{2 c}(p-b)=m_{s}\left(p-p_{\min }\right)[M W]
$$

With considering and simulating whole network and each operator behavior, the gained benefit of operators would be calculated. In a complete competitive market, it had been proved that optimal state of a producer is final proposal as production strategy. This simulated model has 5 bas and 4 operators. It has shown at the end that whole market's benefit is decreased when exercising limitations. In addition, the way by which benefit is distributed has had considerable changes and operator has removed others from market.

In another model (Kashani Zade B. et al. 2006) it has been tried to simulate procedure strategies, using play theories and considering each operator role on market price. Considering this effect on price, supply and benefit of each operator in market comparing states lack of limitation between lines and considering lines limitations would be next step. Goal of all operators of electricity production in competitive environment is increasing production benefit, so procedures would not take any role for consumer. This situation necessitate changing market to a competitive one by exercising policies to prevent monopoly in market and effect prices based on a special strategy of a procedure.

\section{A review on results on Iran electricity market}

Considering information get from offered prices and each region's production and demand, we would examine above results in Iran electricity market. As mentioned before, consumption need do not differ in different month days and in similar hours. Figures 12-18 show price, production and demand for four Mondays (4 weeks) from Tir, 1387 on 3 pm (based on anticipation at local maximum level for Mondays) for all 7 electricity market region.

1. Just region number 6 and 7 can produce at a rate more than their demand for all four days. In other regions production exceeds demand.

2. In region number 6 and 7, fluctuation of prices has not been effective on production and demand rate, so market can exercise authority.

3. In regions number 6 , especially 7 , fluctuation of production and demand is considerable, but in other five regions production and demand volume had little changes during those four weeks. 


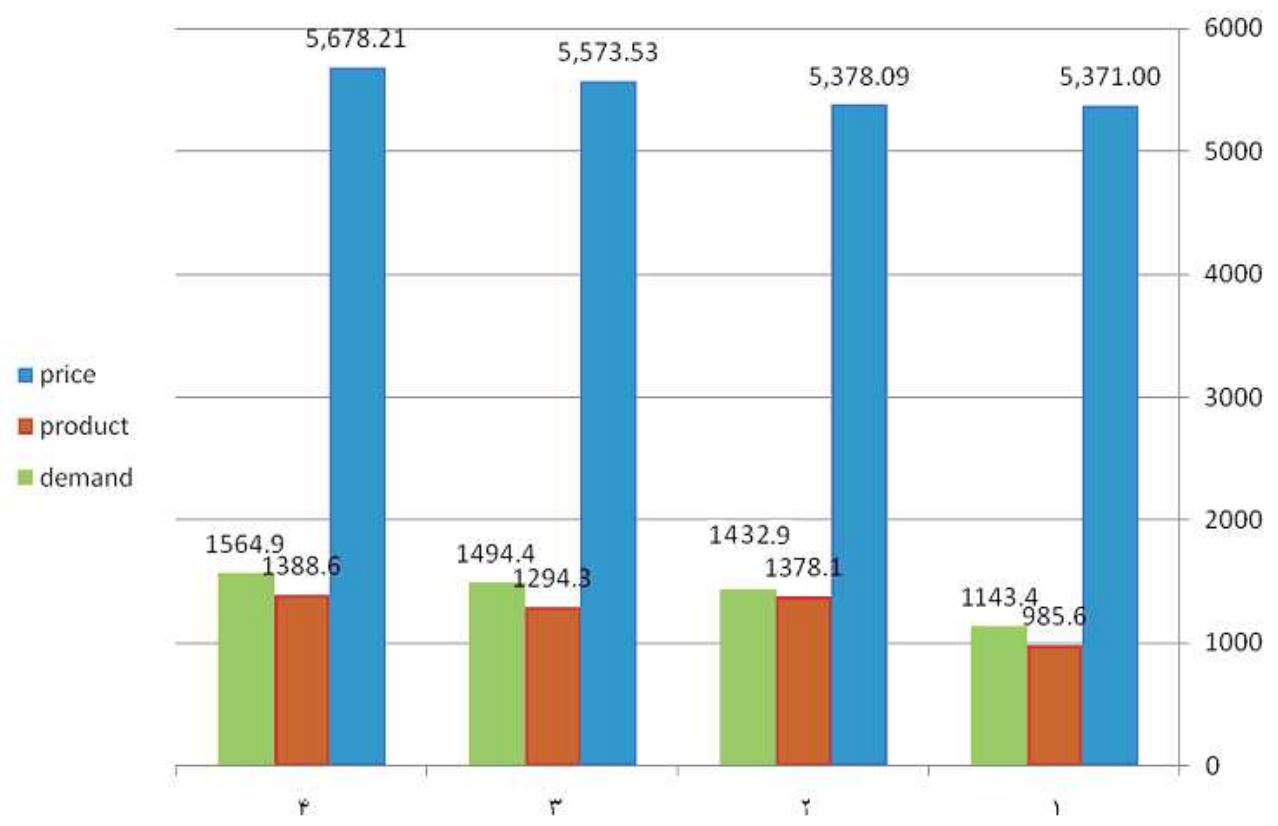

Fig. 12. Comparing three factors in region 1

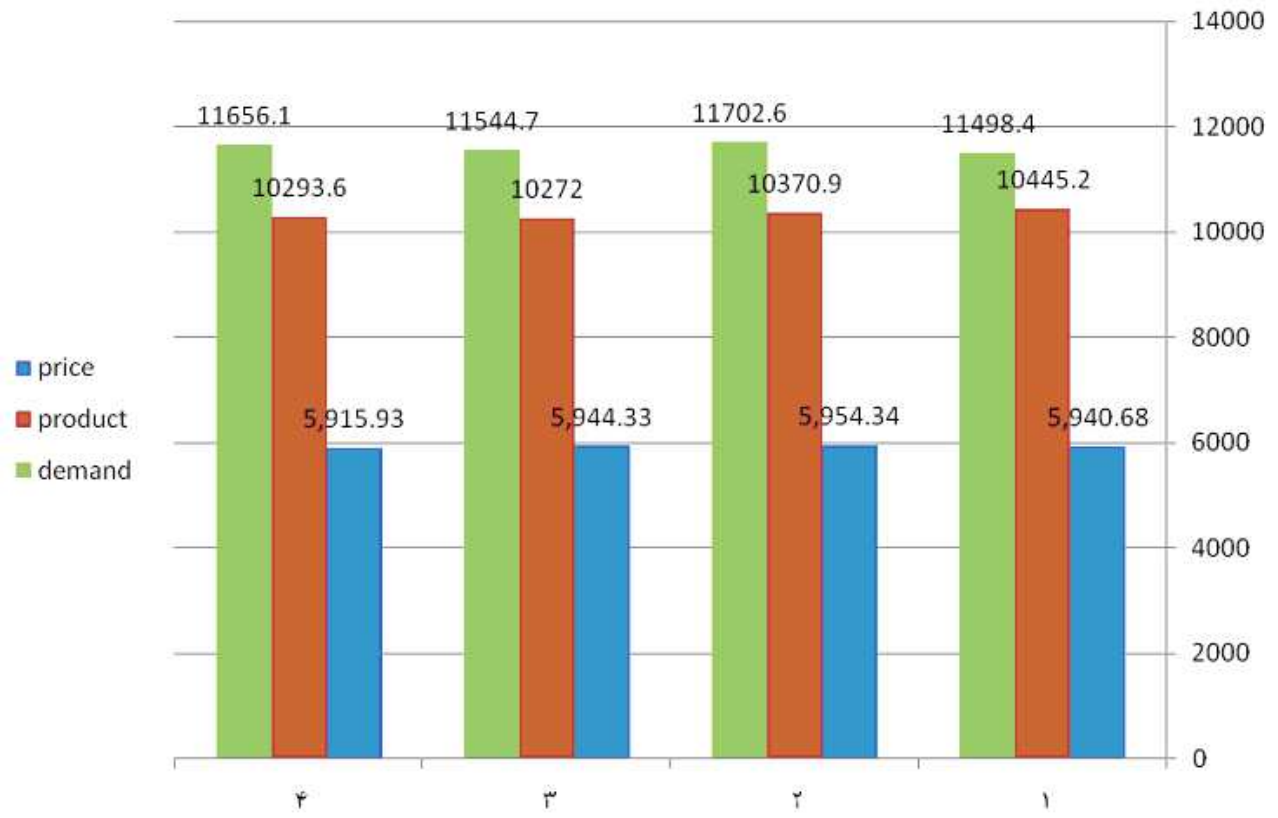

Fig. 13. Comparing three factors in region 2 


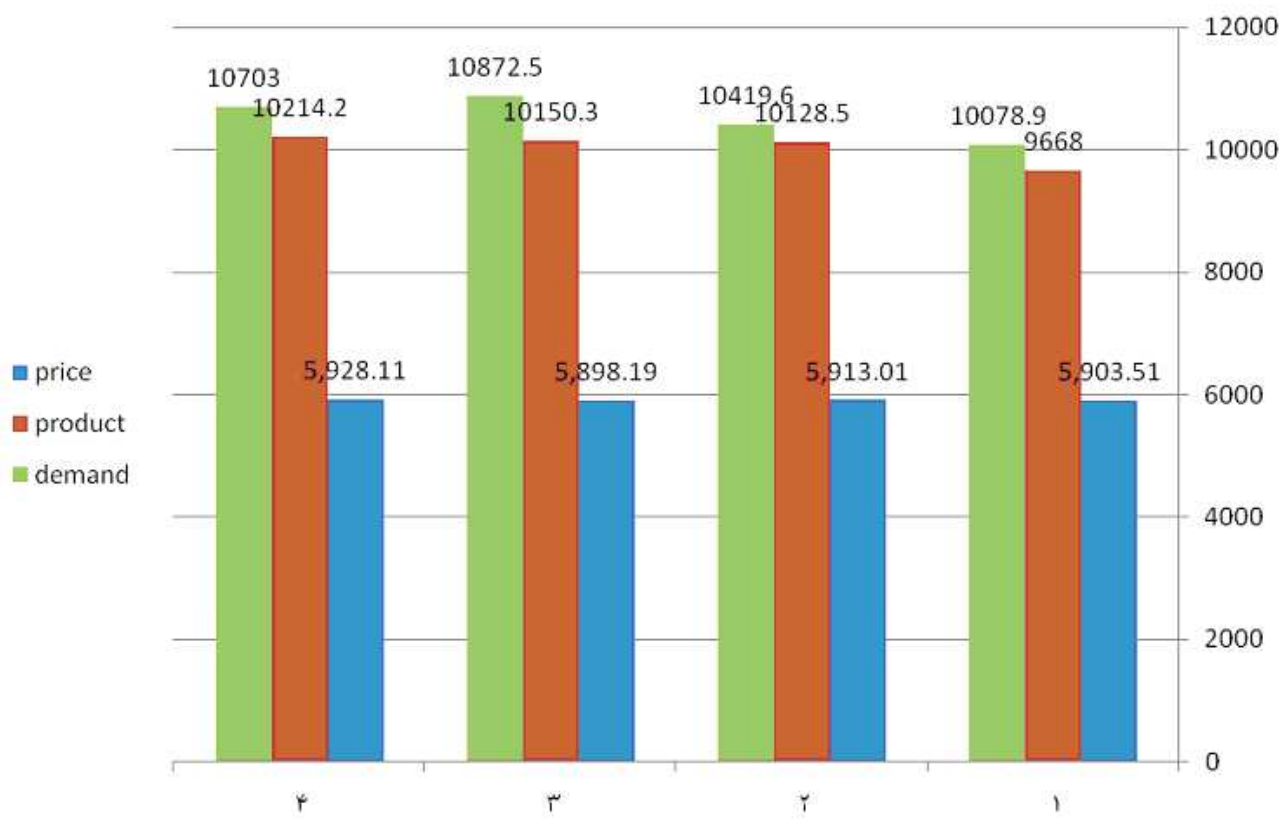

Fig. 14. Comparing three factors in region 3

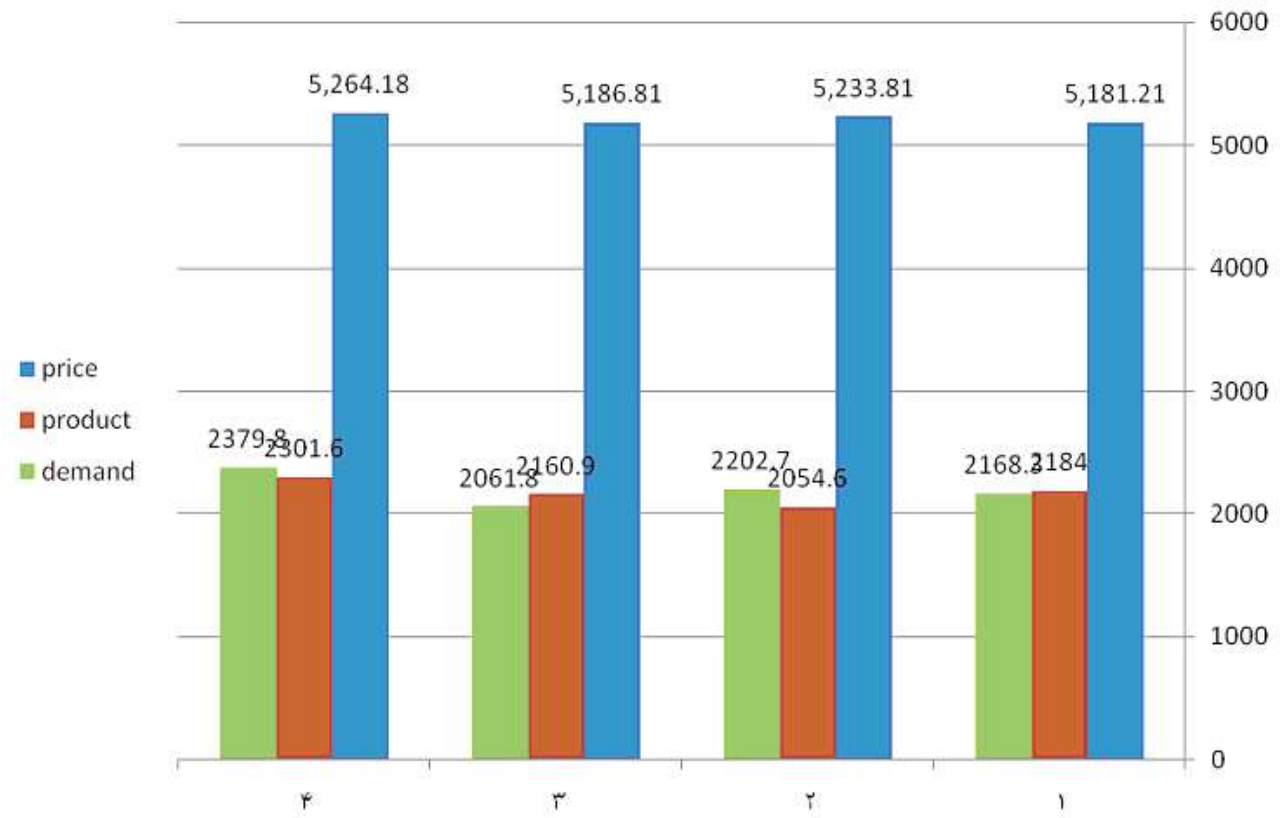

Fig. 15. Comparing three factors in region 4 


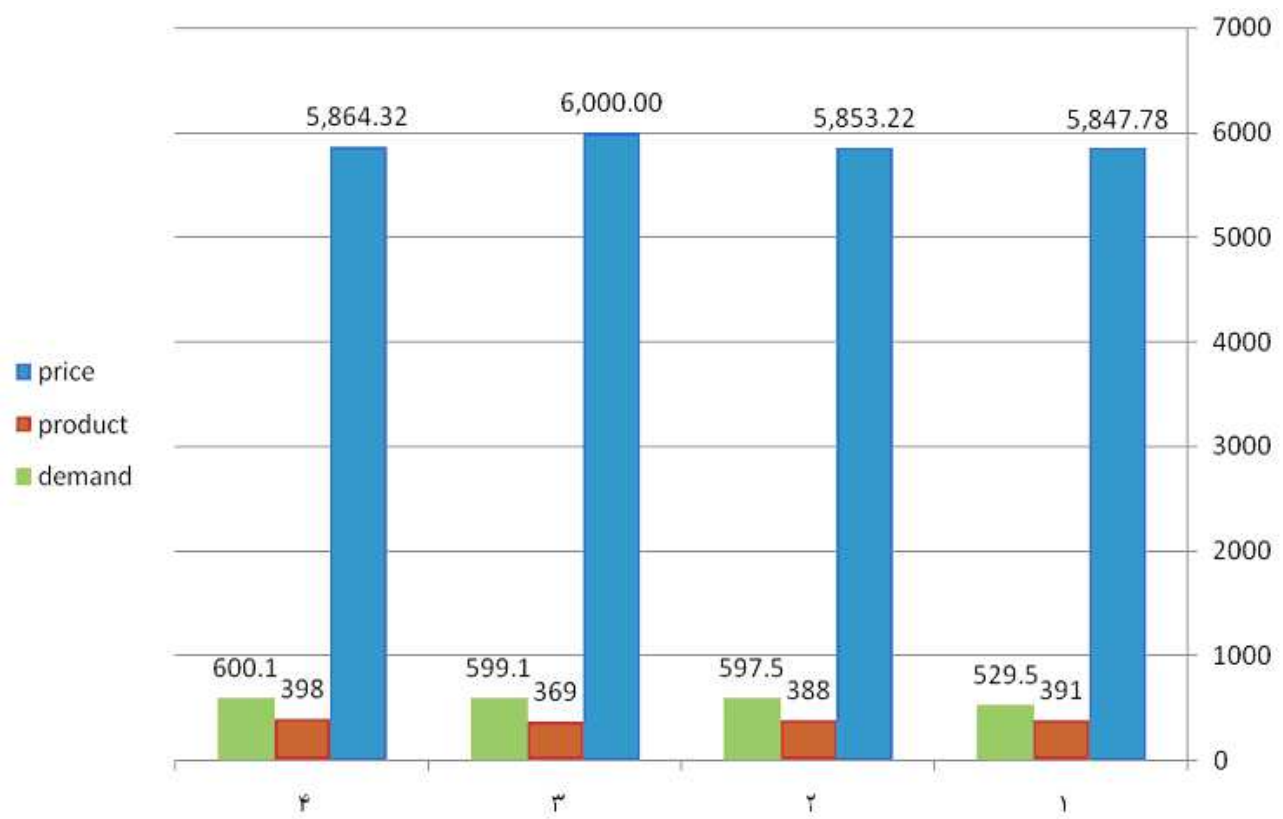

Fig. 16. Comparing three factors in region 5

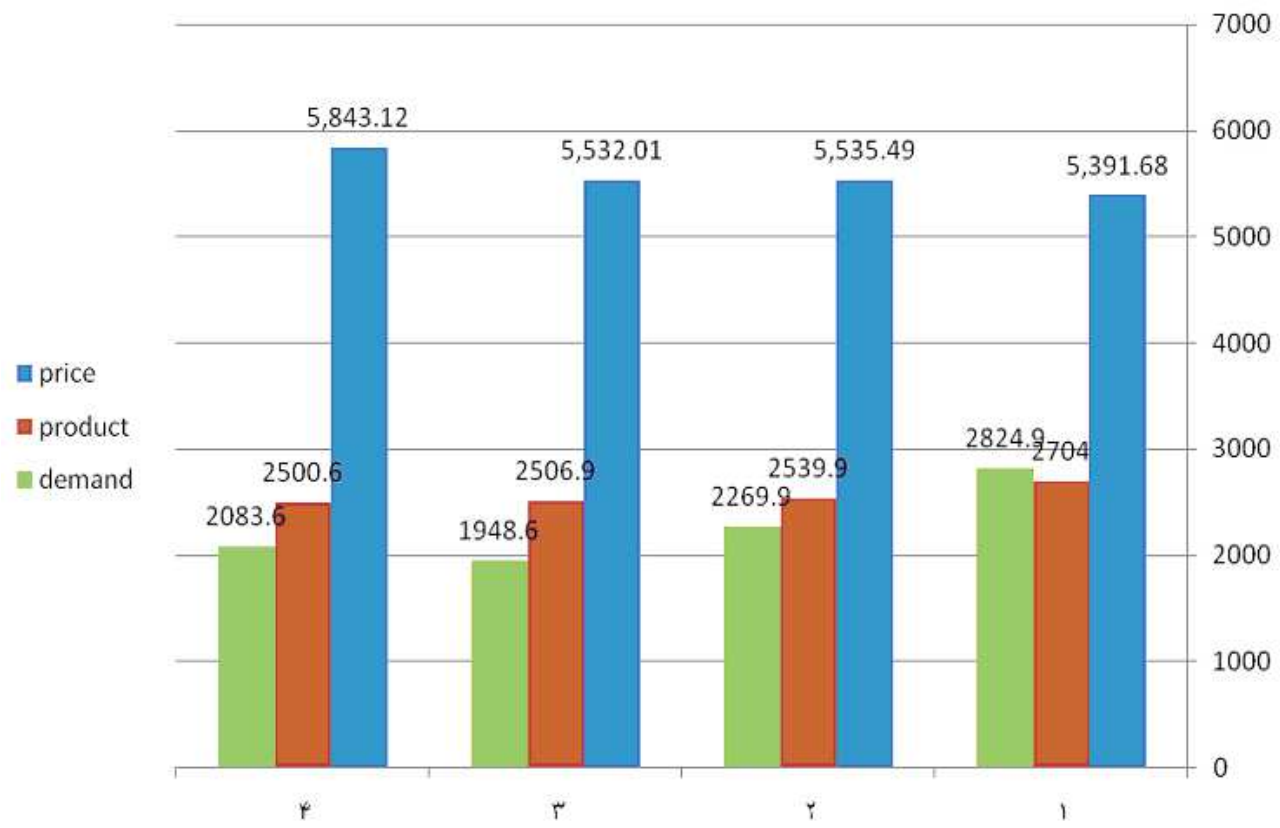

Fig. 17. Comparing three factors in region 6 


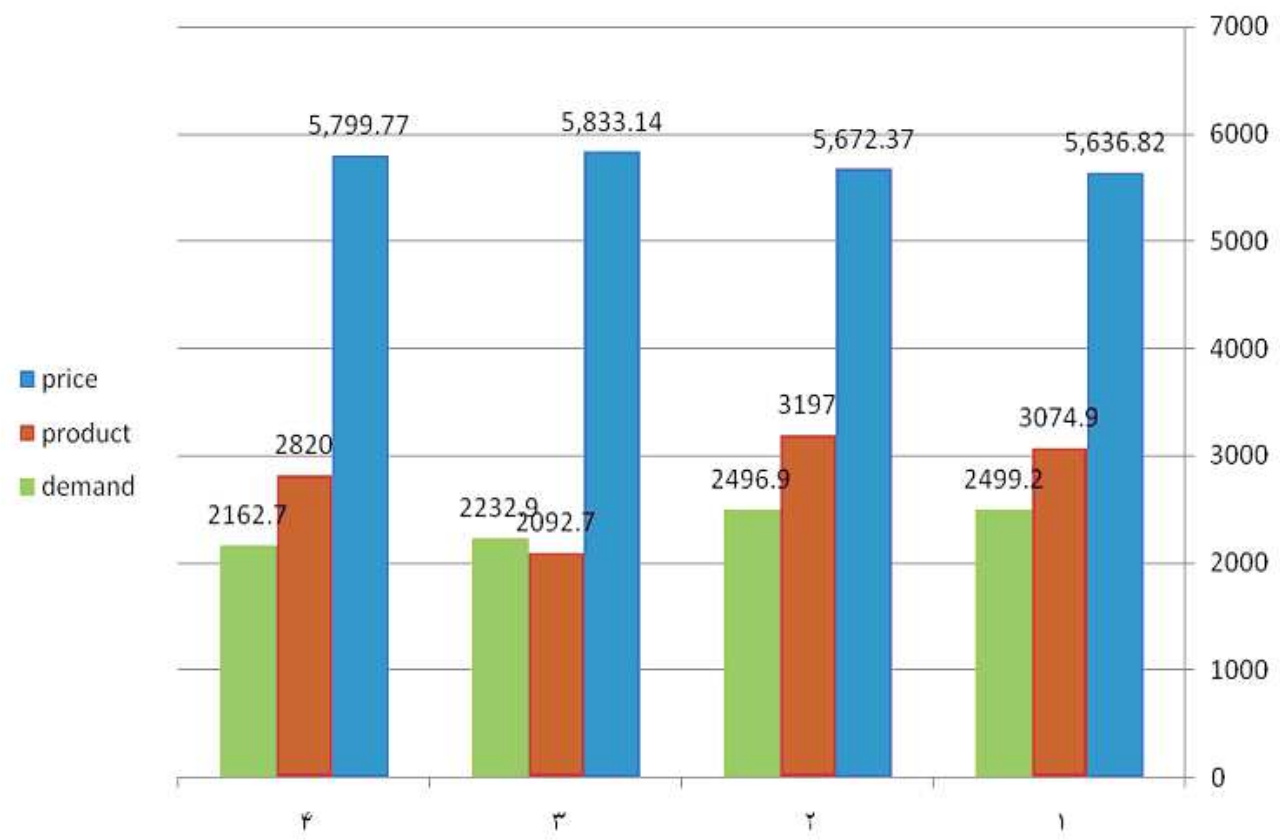

Fig. 18. Comparing three factors in region 7

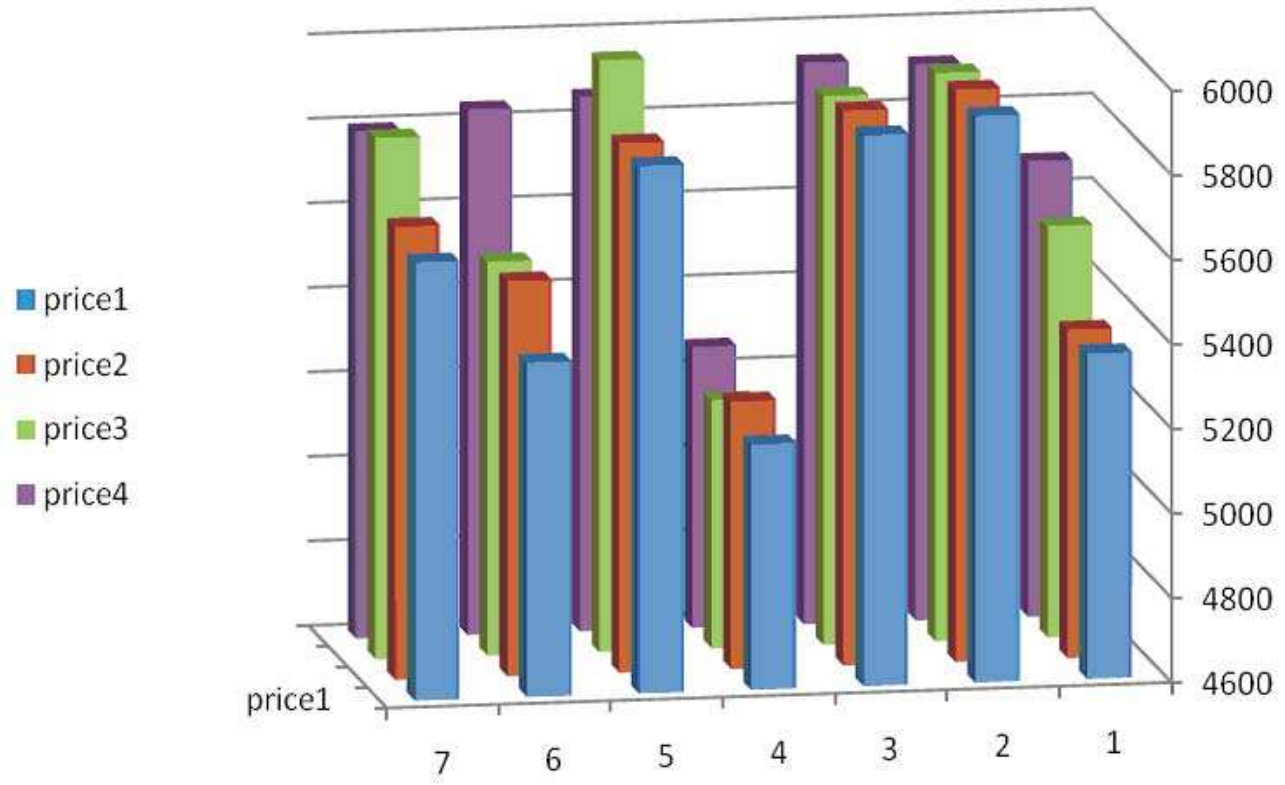

Fig. 19. Comparing price of four weeks in 7 regions 


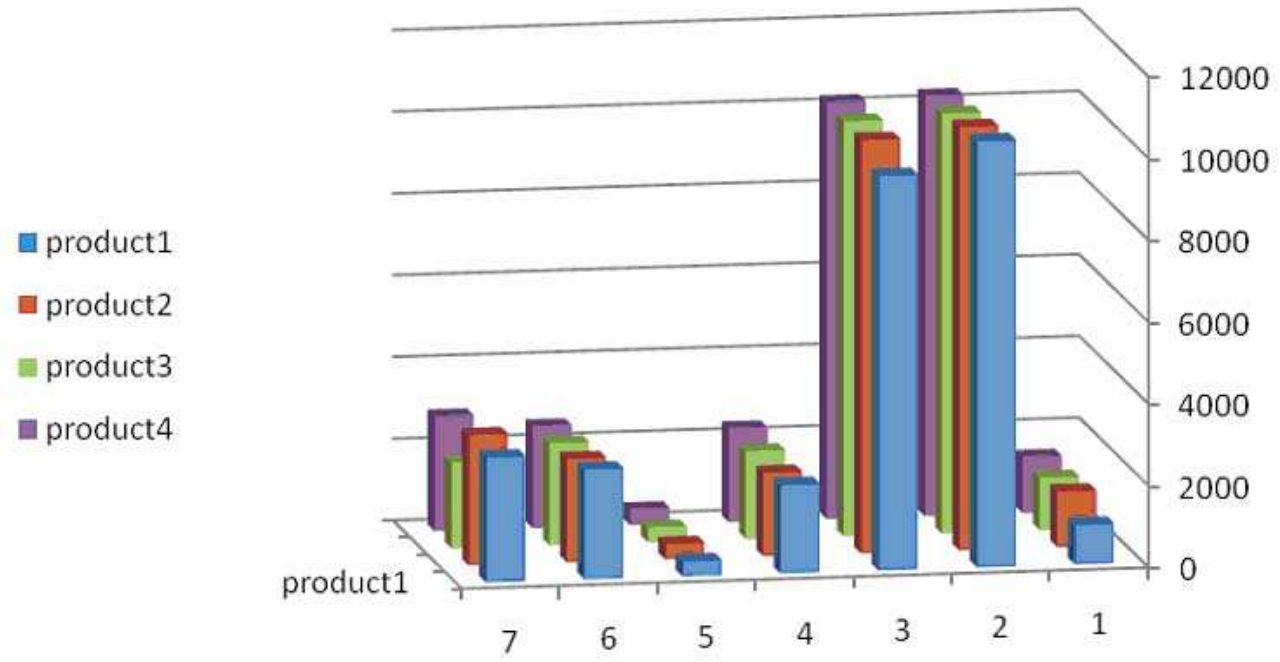

Fig. 20. Comparing production of four weeks in 7 regions

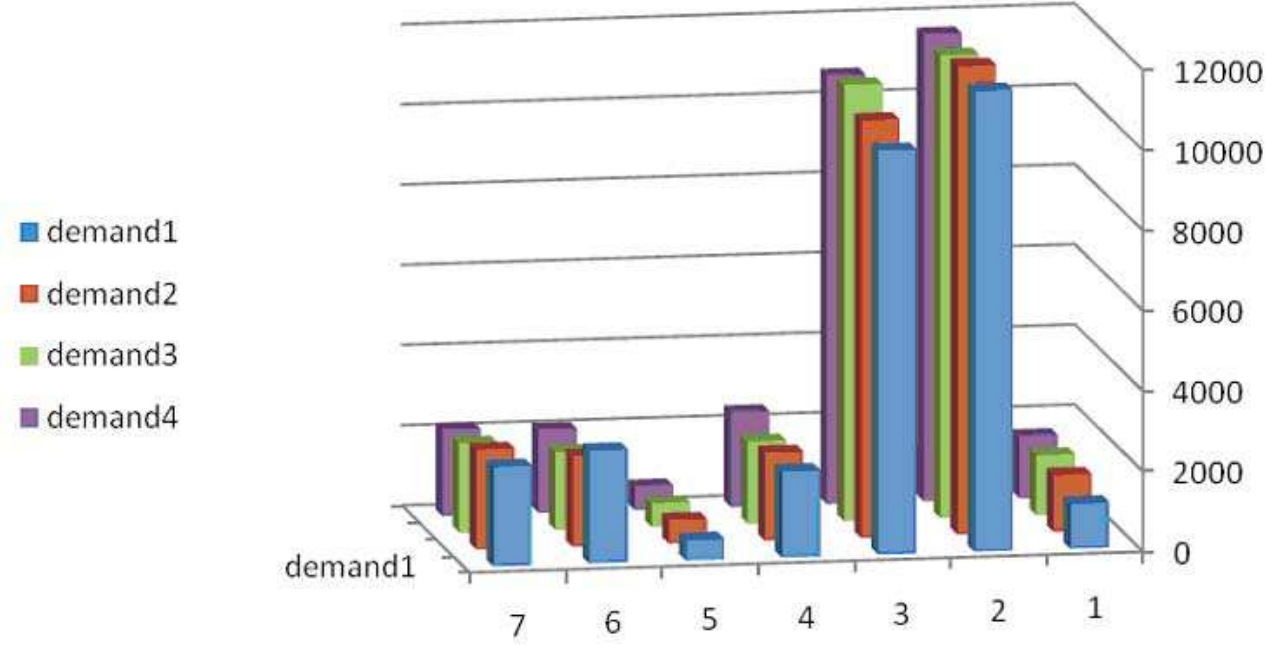

Fig. 21. Comparing demand of four weeks in 7 regionsResults of diagrams 12-18 show:

In figures number 19-21 changes of each price indicator, production and demand is shown separately in 7 regions in 4 days. Diagram 19 shows that highest prices alongside with lowest fluctuation of regions 2 and 3. Region 4 enjoys lowest price and regions 6 and 7 are growing with relatively high fluctuation.

Production and demand changes in figures 20 and 21 shows coordination between production and demand in regions. As seen in these two diagrams just regions number 6 and 7 can produce at a level higher than region demand, price offered in that regions is at a 
low level comparing adjacent regions. These factors show these two regions have potential for market exercising authority.

\section{Results}

Limiting market power is a necessary parameter for power evolution. For doing this at first an exact definition of market helps to recognize existing market power or items which market can exercise authority on.

In this article, SSNIP test has been introduced as a mechanism of defining market, recognizing market boarders and potentials for market exercising authority.

Considering electricity network in Iran and simulated models in Iran electricity market, shows potential exercising authority of market. Iran electricity market has 7 regions, from which according to information in data base, dependant regions number 6 and 7 can do market exercising authority in Iran electricity market. In other five regions recognized as dependent markets, providing demands needs presence of other producers in the region. Offered price in regions number 2 and 3 is at its highest level comparing others because of high demand in those regions.

According to above results, offering some solutions to prevent market exercising authority is necessary. Interrupted bars can decrease system demand in critical circumstances as an operation reservation for a short time. These bars can have role in intensifying competitive circumstances by growth of system margin and decrease of transport lines accumulation. A solution can be growth of power station units as well as departing larger units to smaller ones. Lines accumulation is one factor which can motivate market exercising authority. Planning for re-production and bar cuts are some ways of lines management.

\section{References}

Chi-Keung W. et al, (2006). Bi-directional causality in California's electricity and natural-gas Markets. Energy Policy, 34, 2060-2070

Frayer J., Uledere N. and Lovick S. (2004). Beyond market shares and cost-plus pricing: Designing a horizontal market power mitigation framework for today`s electricity markets. The electricity journal, 1040-6190.

Gujarati D. N. (1995).Granger test, In: Basic Economic. ISBN: 964-03-9330-4, University of Tehran.

Heydari, Kiyomarth (2003). Reform in the Iranian electricity market. $18^{\text {th }}$ electricity conference, 98-f-sea-416.

Izadi, Farhad; Puyan, Seyed Ali (2002). Electricity market simulation, considering transport system limitations. Tehran regional electricity.

Kashani zade, Babak; Ehsan, Mahdi (2006). A review on effects of producers' strategies on electrical energy market price. The first international management and planning energy conference.

Katz M. (2002). Recent Antitrust Enforcement Actions by the U.S. Department of Justice: A Selective Survey of Economic Issues. Review of Industrial Organization, 21: 373-397.

Katz M. (2006) . The Year in Review: Economics at the Antitrust Division, 2005-2006. Review of Industrial Organization, 29:305-326.

Ogzera website (2005). The SSNIP test: some common misconceptions. 
Setayesh Nazar, mehrdad; Saber, Hamze; Javidi, Hosein (2007). Considering effects of interrupted bars on electricity market power mitigation. Sixth National energy Conference, Khordad 1386 (2007), 22 and 23, 98-f-eec-362.

Tabei, Seyed Mohammad Hadi (2005). A new way of calculation of potential transport in electricity market. 20th international electricity conference, 98-f-ptl-179.

Vahabi, Abd-al-Hossein; Barghi Niya, Saeedeh; Vafadar, Naser; Berahmand Por, Homayon (2007). A suggestion for anticipation of short-term bar based on finding out similar days. 22 th international electricity conference, 98-f-pss-610.

Yemane W., (2006). Electricity consumption and economic growth: a time series experience for 17 African countries. Energy Policy 34, 1106-1114. 


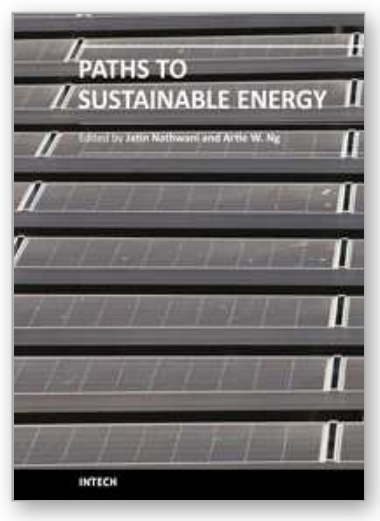

\author{
Paths to Sustainable Energy \\ Edited by Dr Artie $\mathrm{Ng}$
}

ISBN 978-953-307-401-6

Hard cover, 664 pages

Publisher InTech

Published online 30, November, 2010

Published in print edition November, 2010

The world's reliance on existing sources of energy and their associated detrimental impacts on the environment- whether related to poor air or water quality or scarcity, impacts on sensitive ecosystems and forests and land use - have been well documented and articulated over the last three decades. What is needed by the world is a set of credible energy solutions that would lead us to a balance between economic growth and a sustainable environment. This book provides an open platform to establish and share knowledge developed by scholars, scientists and engineers from all over the world about various viable paths to a future of sustainable energy. It has collected a number of intellectually stimulating articles that address issues ranging from public policy formulation to technological innovations for enhancing the development of sustainable energy systems. It will appeal to stakeholders seeking guidance to pursue the paths to sustainable energy.

\title{
How to reference
}

In order to correctly reference this scholarly work, feel free to copy and paste the following:

Zahra Tavassoli Hojati and Seyed Farid Ghaderi (2010). Identifying Regional Behavior Impacts of Electricity Generation in Electricity Market with SSNIP and Granger Test, Paths to Sustainable Energy, Dr Artie Ng (Ed.), ISBN: 978-953-307-401-6, InTech, Available from: http://www.intechopen.com/books/paths-to-sustainableenergy/identifying-regional-behavior-impacts-of-electricity-generation-in-electricity-market-with-ssnip-and

\section{INTECH}

open science | open minds

\author{
InTech Europe \\ University Campus STeP Ri \\ Slavka Krautzeka 83/A \\ 51000 Rijeka, Croatia \\ Phone: +385 (51) 770447 \\ Fax: +385 (51) 686166 \\ www.intechopen.com
}

\author{
InTech China \\ Unit 405, Office Block, Hotel Equatorial Shanghai \\ No.65, Yan An Road (West), Shanghai, 200040, China \\ 中国上海市延安西路65号上海国际贵都大饭店办公楼405单元 \\ Phone: +86-21-62489820 \\ Fax: +86-21-62489821
}


(C) 2010 The Author(s). Licensee IntechOpen. This chapter is distributed under the terms of the Creative Commons Attribution-NonCommercialShareAlike-3.0 License, which permits use, distribution and reproduction for non-commercial purposes, provided the original is properly cited and derivative works building on this content are distributed under the same license. 